\title{
The expression and significance of histone lysine methylation in endometrial cancer
}

\author{
QING LI ${ }^{1}$, NAN JIA $^{1}$, XIANG TAO ${ }^{2}$, KEQIN HUA $^{1,3}$ and WEIWEI FENG ${ }^{1,3}$ \\ Departments of ${ }^{1}$ Gynecology and ${ }^{2}$ Pathology, Obstetrics and Gynecology Hospital, Fudan University; \\ ${ }^{3}$ Shanghai Key Laboratory of Female Reproductive Endocrine-Related Disease, Fudan University, Shanghai 200011, P.R. China
}

Received April 13, 2016; Accepted July 7, 2017

DOI: 10.3892/ol.2017.6979

\begin{abstract}
Histone modifications of lysine residues have been implicated as having diagnostic and/or prognostic significance in numerous types of cancer. In the present study, the significance of the histone $\mathrm{H} 3$ methylation of lysine 4 (H3K4) and lysine 27 (H3K27) were investigated in endometrial cancer. Specifically, immunohistochemical analysis was used to detect the cellular expression levels of H3K27 trimethylation (H3K27me3), H3K4 trimethylation (H3K4me3) and H3K4 dimethylation (H3K4me2) in glandular epithelial tissues and stromal tissues. The association between the methylation levels of histone markers and clinicopathological parameters were analyzed. The results demonstrated that in epithelial cells, H3K4me2 and H3K4me3 exhibited the highest levels in endometrial cancer, followed by precancerous lesions and a normal endometrium. Low expression levels of H3K4me2 in glandular epithelium of endometrial cancer were significantly associated with a clinical early International Federation of Gynecology and Obstetrics stage $(\mathrm{P}=0.006)$. For stromal tissues, the expression level of H3K27me 3 in Type 1 endometrial cancer was significantly lower compared with that in the normal endometrium $(\mathrm{P}=0.043)$ and precancerous lesions $(\mathrm{P}<0.001)$. The expression level of $\mathrm{H} 3 \mathrm{~K} 4 \mathrm{me} 2$ was significantly lower in the stroma of Type 1 and 2 cancer compared within the normal endometrium $(\mathrm{P}=0.005)$. A low $\mathrm{H} 3 \mathrm{~K} 4 \mathrm{me} 3$ expression level in the stroma of endometrial cancer tissues was associated with $\mathrm{P} 53$-negativity $(\mathrm{P}=0.032)$. In conclusion, the cellular expression levels of histone $\mathrm{H} 3$ methylation were differentially presented in glandular epithelial and
\end{abstract}

Correspondence to: Professor Weiwei Feng, Department of Gynecology, Obstetrics and Gynecology Hospital, Fudan University, 419 Fangxie Road, Shanghai 200011, P.R. China

E-mail:wfeng7347@aliyun.com

Abbreviations: H3K27me3, trimethylation of histone 3 lysine 27; $\mathrm{H} 3 \mathrm{~K} 4 \mathrm{me}$ 2, dimethylation of histone 3 lysine 4; H3K4me3, trimethylation of histone 3 lysine 4; LVSI, lymph-vascular space involvement; HCC, hepatocellular carcinoma

Key words: endometrial cancer, histone modifications, histone 3 lysine methylation stromal elements in endometrial tissues. A low expression level of activation marker $\mathrm{H} 3 \mathrm{~K} 4 \mathrm{me} 2$ in glandular epithelium defined a subset of patients with early-stage endometrial adenocarcinoma and may have potential prognostic value.

\section{Introduction}

Endometrial cancer poses a threat for the health of females, with $\sim 320,000$ newly diagnosed cases each year worldwide (1). A total of 76,000 patients eventually succumb to this malignancy per year, making it the sixth most common type of cancer in females (2). In view of the increasing incidence, understanding how this malignancy is initiated and progresses is of great importance, and this knowledge is required. It is now well established that in addition to genetic changes, epigenetic alterations, including DNA methylation and post-translational histone modifications, which control chromatin accessibility and gene activity, are associated with the aberrant expression level of oncogenic or tumor-suppressor genes. Chromatin-modifying enzymes can catalyze reversible modifications of histones, in which lysine methylation serve an important role.

A repression marker, histone $\mathrm{H} 3$ lysine 27 trimethylation (H3K27me3), and two activating markers, histone H3 lysine 4 dimethylation (H3K4me2) and histone H3 lysine 4 trimethylation (H3K4me3), were selected as they have been revealed to possess associations with cancer (3-5). These, and other modifications, generate a combinatorial histone code that demarcates chromatin regions for transcription activation or repression. Recently, cellular patterns of histone modifications have been demonstrated to be prognostic indicators for numerous types of tumors, including prostate (6), kidney (7), lung (8), gastric (9), ovarian (10) and breast cancer (11); however, little is known about the global alteration of histone status during tumorigenesis, and cancer progression in endometrial cancer. The present study therefore aimed to assess the clinical significance of selected histone modifications in endometrial tissues, including the normal endometrium, precancerous lesions and endometrial cancer. The association between histone modifications and the clinicopathological data was analyzed in the present study.

\section{Materials and methods}

Research subject. After obtaining approval from the Obstetrics and Gynecology Hospital of Fudan University (Shanghai, 


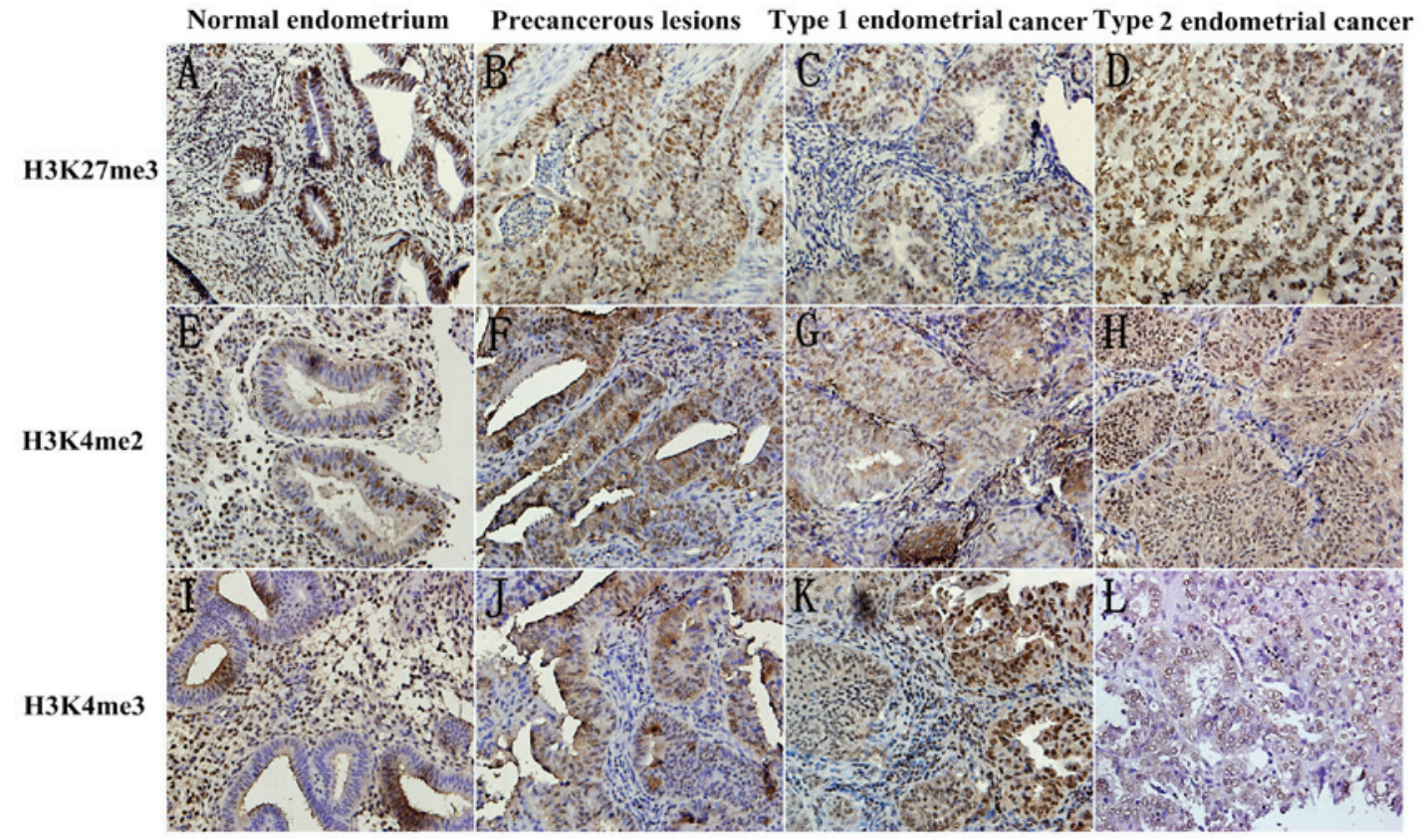

Figure 1. Representative images of immunohistochemistry staining. (A) Normal endometrium, (B) precancerous lesions, (C) Type 1 endometrial cancer and (D) Type 2 endometrial cancer tissues stained forH3K27me3. (E) Normal endometrium, (F) precancerous lesions, (G) Type 1 endometrial cancer and (H) Type 2 endometrial cancer tissues stained for H3K4me2. (I) Normal endometrium, (J) precancerous lesions, (K) Type 1 endometrial cancer and (L) Type 2 endometrial cancer tissues stained for H3K4me3. All images were captured at magnification x200 using light microscopy. H3K27me3, histone H3 lysine 27 trimethylation; H3K4me2, histone H3 lysine 4 dimethylation; H3K4me3, histone H3 lysine 4 trimethylation.

China) Ethics Committee, 99 endometrial tissues (including 24 normal endometrial samples, 18 precancerous lesions, and 44 Type 1 and 13 Type 2 endometrial cancer samples) were obtained from patients treated in the Obstetrics and Gynecology Hospital of Fudan University between June 2008 and December 2012. The mean age of all patients enrolled was $51.7 \pm 10.2$ years. The mean ages of the normal group, precancerous group, and type 1 and type 2 cancer groups were $47.5 \pm 7.2,44.3 \pm 7.7,56.4 \pm 8.8$, and $55.15 \pm 12.4$ years, respectively. Written informed consent was obtained from all patients prior to enrollment in the present study. Normal tissues, including 12 proliferative, 9 secretory and 3 atrophic endometrial tissues, were obtained from patients who had benign disease, including adenomyosis or myoma, and 18 precancerous lesions, including 9 simple hyperplasia, 2 complex hyperplasia and 7 atypical hyperplasia tissues from patients who had irregular bleeding. Hematoxylin and eosin (H\&E) (hematoxylin for $5 \mathrm{~min}$ and eosin for $10 \mathrm{sec}$ at temperature between 20-2 $4^{\circ} \mathrm{C}$ ) stained tissue sections adjacent to the tissue sections obtained for immunohistochemical staining of all specimens were reviewed by an experienced pathologist to confirm the diagnosis. For patients with endometrial cancer, the clinicopathological parameters, including International Federation of Gynecology and Obstetrics (FIGO) stage, tumor grade, depth of myometrial invasion and p53, as well as estrogen receptor (ER), progesterone receptor (PR) and lymph-vascular space invasion (LVSI) evaluations, were collected. The surgical pathology stage was determined in accordance with the 2009 FIGO guidelines (12).

Immunohistochemistry. Antigen retrieval and antibody dilutions were optimized prior to the initiation of the study (Mingrui Biotech, Shanghai, China). Diagnosis of each case was made by two experienced pathologists without discrepancy. To ensure uniformity, all tissue sections were processed synchronically. The H\&E tissue sections $(4 \mu \mathrm{m})$ adjacent to the sections used for immunohistochemistry assessment were used for pathological diagnosis. The working dilutions of anti-H3K27me3 antibodies (cat. no. CST 9733s; Cell Signaling Technology, Inc., Danvers, MA, USA), anti-H3K4me2 antibodies (cat. no. Ab32356; Abcam, Cambridge, UK) and anti-H3K4me3 antibodies (cat. no. Ab8580; Abcam) were 1:100. Endogenous peroxidase activity was blocked using $0.3 \% \mathrm{H}_{2} \mathrm{O}_{2}$. Slides were washed and incubated with the biotinylated secondary antibody (polyclonal goat anti-rabbit; Histostain-Plus IHC kit; Mingrui Biotech, Shanghai, China) for $45 \mathrm{~min}$ at $37^{\circ} \mathrm{C}$ and washed with PBS.

Procedures were performed using an immunohistochemistry kit (MR Biotech Ltd., Shanghai, China), according to the manufacturer's protocol. Tissue staining intensities were assessed using double-blinded quantitative scoring. For the semi-quantitative analysis, 5 fields of each slide were randomly selected under magnification, x10 and further read under magnification, x40 using light microscope. Positive staining refers to dark brown granules within the nuclear region, with or without brown granules in the cytoplasm. The percentages of positive cells were assessed independently by two observers and the mean values of their results was used for evaluation.

Statistical analysis. All data were statistically analyzed by an independent-sample t-test (Students' t-test) or one-way analysis of variance (ANOVA, Bonferroni used as post-hoc test) using SPSS version 20.0 (IBM Corp., Armonk, NY, USA). The data were presented as mean \pm standard deviation. $\mathrm{P}<0.05$ was considered to indicate a statistically significant difference. 

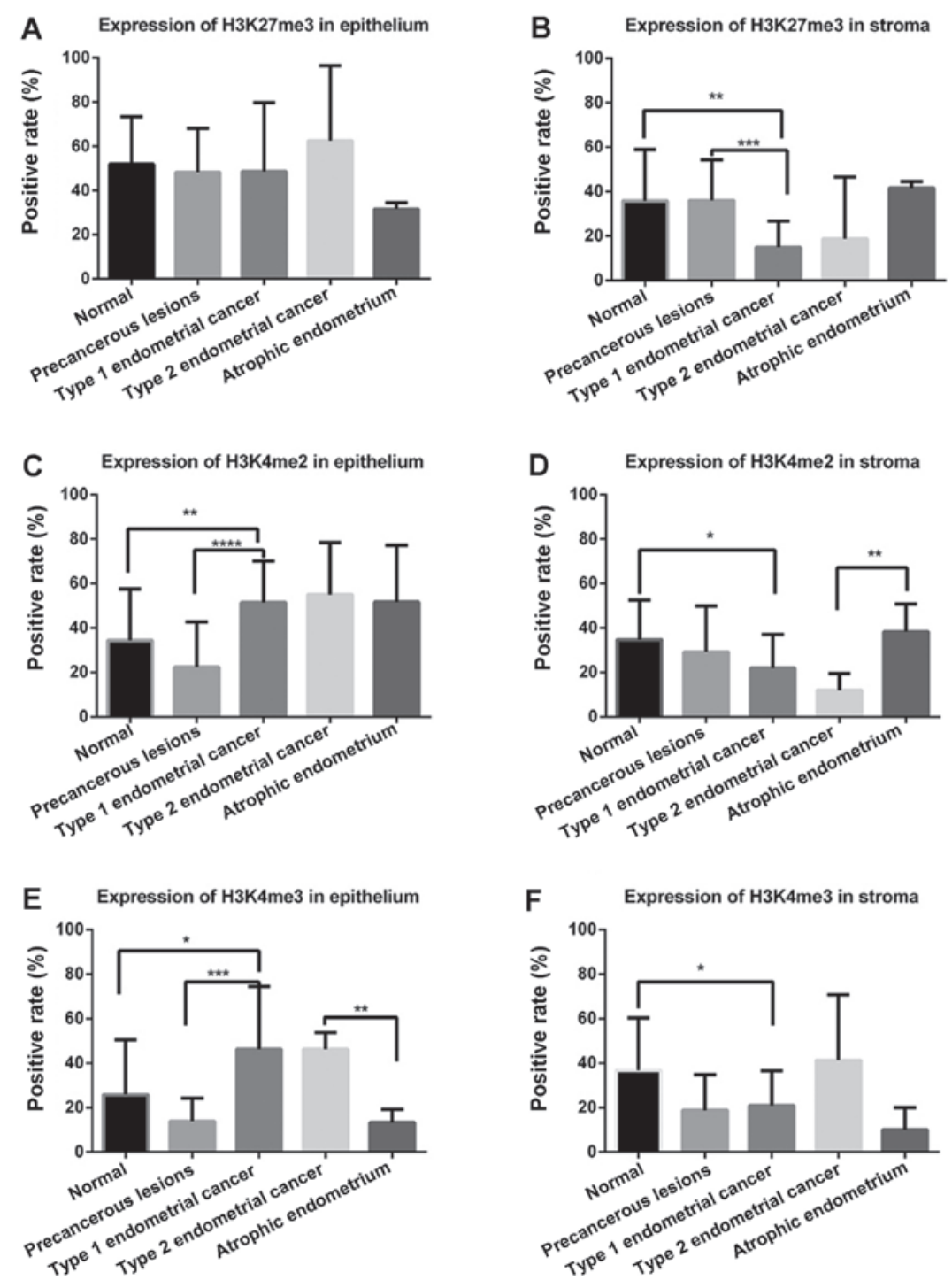

Figure 2. Semi-quantified IHC results of H3K27me3, H3K4me2 and H3K4me3 markers. The expression levels of three histone methylation markers in endometrial tissue that were semi-quantified according to the IHC results and compared between various groups. The $\mathrm{X}$ axis represents different tissue groups and the $\mathrm{Y}$ axis represents positive rates of the three markers. The expression level of $\mathrm{H} 3 \mathrm{~K} 27 \mathrm{me} 3$ in (A) in the epithlium and (B) stroma. The expression level of H3K4me2 in (C) in the epithelium and (D) stroma. The expression level of H3K4me3 in (E) in the epithlium and (F) stroma. ${ }^{* * *} \mathrm{P}<0.0001,{ }^{* * *} \mathrm{P}<0.001,{ }^{* *} \mathrm{P}<0.01$, ${ }^{*} \mathrm{P}<0.05$. IHC, immunohistochemistry; H3K27me3, histone H3 lysine 27 trimethylation; H3K4me2, histone H3 lysine 4 dimethylation; H3K4me3, histone H3 lysine 4 trimethylation.

\section{Results}

Samples from 24 normal endometrial tissues, 18 precancerous lesions, and 44 type 1 and 17 type 2 endometrial cancer tissues were retrieved. The present study observed the methylation expression level of three markers, H3K27me3, H3K4me2 and H3K4me3, by immunohistochemistry in the epithelial, and stromal compartments of tissues. Fig. 1 Presents the representative images.

The patients with type 2 cancer were postmenopausal; therefore, the present study compared the methylation levels of the markers in two sessions: Type 1 cancer with a normal endometrium and hyperplasia tissue; and type 2 cancer with an atrophic endometrium. For normal endometrium, the present study used one-way ANOVA to determine whether there were significant differences among the proliferative, secretory and atrophic endometrium tissues. As presented in Fig. 2A, in glandular epithelium, H3K27me3 demonstrated no difference in cancerous tissues and noncancerous tissues; however, in stromal tissue, the expression level of H3K27me3 was lowest in the stroma of Type 1 endometrial cancer compared with in the normal endometrium $(\mathrm{P}=0.002)$ and precancerous lesions ( $\mathrm{P}=0.001$; Fig. 2B).

H3K4me2 was highly expressed in the glandular epithelium of Type 1 endometrial cancer compared with in the normal endometrium $(\mathrm{P}=0.007)$ and precancerous lesions $(\mathrm{P}<0.001$; Fig. 2C). Conversely, in the stroma, a lower expression level of $\mathrm{H} 3 \mathrm{~K} 4 \mathrm{me} 2$ was identified in Type 1 endometrial cancer compared with precancerous lesions $(\mathrm{P}=0.012$; Fig. 2D). Similarly, a lower expression level of H3K4me2 in the stroma was demonstrated in Type 2 endometrial cancer compared with intheatrophic endometrium $(\mathrm{P}=0.009)$.

In glandular epithelium (Fig. 2E), the expression level of H3K4me3 was higher in Type 1 endometrial cancer compared 
Table I. Association between the expression levels of histone modification markers and clinicopathological features in glandular epithelium of endometrial cancer.

\begin{tabular}{|c|c|c|c|c|c|c|}
\hline Clinicopathological characteristic & H3K27me3 & P-value ${ }^{a}$ & H3K4me2 & P-value ${ }^{b}$ & H3K4me3 & P-value ${ }^{c}$ \\
\hline FIGO stage & & 0.325 & & 0.006 & & 0.814 \\
\hline I & $0.58 \pm 0.22$ & & $0.42 \pm 0.18$ & & $0.47 \pm 0.27$ & \\
\hline II-IV & $0.49 \pm 0.31$ & & $0.60 \pm 0.20$ & & $0.49 \pm 0.30$ & \\
\hline Tumor grade & & NS & & NS & & NS \\
\hline G1 & $0.56 \pm 0.27$ & & $0.47 \pm 0.14$ & & $0.47 \pm 0.29$ & \\
\hline $\mathrm{G} 2$ & $0.63 \pm 0.16$ & & $0.61 \pm 0.26$ & & $0.48 \pm 0.21$ & \\
\hline G3 & $0.43 \pm 0.33$ & & $0.54 \pm 0.17$ & & $0.43 \pm 0.33$ & \\
\hline Type 2 & $0.63 \pm 0.34$ & & $0.55 \pm 0.23$ & & $0.46 \pm 0.08$ & \\
\hline Endometrial infiltration & & NS & & NS & & NS \\
\hline Limited to endometrium & $0.58 \pm 0.39$ & & $0.33 \pm 0.15$ & & $0.29 \pm 0.30$ & \\
\hline$<1 / 2$ & $0.58 \pm 0.19$ & & $0.44 \pm 0.17$ & & $0.44 \pm 0.29$ & \\
\hline$\geq 1 / 2$ & $0.47 \pm 0.34$ & & $0.60 \pm 0.20$ & & $0.32 \pm 0.33$ & \\
\hline P53 & & 0.105 & & 0.339 & & 0.631 \\
\hline Negative & $0.57 \pm 0.23$ & & $0.48 \pm 0.19$ & & $0.39 \pm 0.30$ & \\
\hline Positive & $0.76 \pm 0.13$ & & $0.58 \pm 0.21$ & & $0.46 \pm 0.40$ & \\
\hline ER & & 0.193 & & 0.078 & & 0.723 \\
\hline Negative & $0.40 \pm 0.33$ & & $0.61 \pm 0.20$ & & $0.37 \pm 0.34$ & \\
\hline Positive & $0.61 \pm 0.20$ & & $0.46 \pm 0.19$ & & $0.42 \pm 0.30$ & \\
\hline PR & & 0.773 & & 0.653 & & 0.460 \\
\hline Negative & $0.53 \pm 0.39$ & & $0.60 \pm 0.43$ & & $0.30 \pm 0.32$ & \\
\hline Positive & $0.49 \pm 0.29$ & & $0.47 \pm 0.17$ & & $0.42 \pm 0.31$ & \\
\hline LVSI & & 0.182 & & 0.682 & & 0.234 \\
\hline No & $0.60 \pm 0.24$ & & $0.51 \pm 0.17$ & & $0.42 \pm 0.28$ & \\
\hline Yes & $0.48 \pm 0.26$ & & $0.48 \pm 0.21$ & & $0.28 \pm 0.28$ & \\
\hline
\end{tabular}

Data were presented as the mean \pm standard deviation. ${ }^{\mathrm{a} C o m p a r i s o n}$ between the level of $\mathrm{H} 3 \mathrm{~K} 27 \mathrm{me} 3$ in glandular epithelium of endometrial cancer in different indexes, such as FIGO stage I and FIGO stage II-IV. ${ }^{\mathrm{b}}$ Comparison between the level of H3K4me2 in glandular epithelium of endometrial cancer in different indexes. ${ }^{\circ}$ Comparison between the level of $\mathrm{H} 3 \mathrm{~K} 4 \mathrm{me} 3$ in glandular epithelium of endometrial cancer in different indexes. NS, not significant; FIGO, International Federation of Gynecology and Obstetrics; ER, estrogen receptor; PR, progesterone receptor; LVSI, lymph-vascular space invasion; H3K27me3, histone H3 lysine 27 trimethylation; H3K4me2, histone H3 lysine 4 dimethylation; H3K4me3, histone H3 lysine 4 trimethylation.

within the normal endometrium $(\mathrm{P}=0.02)$ and precancerous lesions $(\mathrm{P}<0.001)$, which was similar to the expression level of H3K4me2. The H3K4me3 expression levels were also higher in epithelial cells of Type 2 endometrial cancer compared within the atrophic endometrium $(\mathrm{P}=0.002)$. Lower expression levels of $\mathrm{H} 3 \mathrm{~K} 4 \mathrm{me} 3$ in the stroma were revealed in Type 1 endometrial cancer compared with in the normal endometrium ( $\mathrm{P}=0.03$; Fig. 2F).

Subsequently, the present study investigated the association between the expression levels of histone modification markers and clinicopathological features in endometrial cancer.

As presented in Tables I and II, there were no significant differences between the H3K27me3 expression levels and clinical characteristics, including FIGO stage, tumor grade, depth of myometrial invasion, P53, ER, PR, and LVSI. In the epithelial elements of Type 1 endometrial cancer, a low expression level of H3K4me2 was associated with an early FIGO stage $(\mathrm{P}=0.006)$. In the stroma of Type 2 endometrial cancer, a low expression level of H3K4me3 was associated with P53 negativity $(\mathrm{P}=0.032)$.

\section{Discussion}

Histone is the key component of nucleosomes and serves a significant role in epigenetics. Numerous epigenetic studies have investigated the role of DNA methylation (13-15), but there are few reports regarding histone methylation and its significance in endometrial cancer. To the best of our knowledge, the present study analyzed the expression of $\mathrm{H} 3 \mathrm{~K} 4 \mathrm{me} 2, \mathrm{H} 3 \mathrm{~K} 4 \mathrm{me} 3$ and $\mathrm{H} 3 \mathrm{~K} 27 \mathrm{me} 3$ in endometrial tissues by immunohistochemistry for the first time, assessing the potential association between endometrial cancer progression, and the expression levels of these three markers.

The trimethylation of $\mathrm{H} 3 \mathrm{~K} 27$ is associated with the transcriptional inhibition of genes. Enhancer of zeste 2 polycomb repressive complex 2 subunit, a methyl-transferase for $\mathrm{H} 3 \mathrm{~K} 27$, is upregulated in a variety of tumors and serves an 
Table II. Association between the expression levels of histone modification markers and clinicopathological features in the stroma of endometrial cancer.

\begin{tabular}{|c|c|c|c|c|c|c|}
\hline Clinicopathological characteristic & H3K27me3 & P-value ${ }^{a}$ & $\mathrm{H} 3 \mathrm{~K} 4 \mathrm{me} 2$ & P-value ${ }^{b}$ & $\mathrm{H} 3 \mathrm{~K} 4 \mathrm{me} 3$ & P-value \\
\hline FIGO stage & & 0.514 & & 0.910 & & 0.437 \\
\hline I & $0.18 \pm 0.16$ & & $0.20 \pm 0.15$ & & $0.27 \pm 0.17$ & \\
\hline II-IV & $0.15 \pm 0.13$ & & $0.20 \pm 0.07$ & & $0.22 \pm 0.17$ & \\
\hline Tumor grade & & NS & & NS & & NS \\
\hline G1 & $0.16 \pm 0.12$ & & $0.22 \pm 0.19$ & & $0.22 \pm 0.15$ & \\
\hline $\mathrm{G} 2$ & $0.08 \pm 0.03$ & & $0.17 \pm 0.05$ & & $0.26 \pm 0.18$ & \\
\hline G3 & $0.18 \pm 0.15$ & & $0.27 \pm 0.12$ & & $0.15 \pm 0.15$ & \\
\hline Type 2 & $0.19 \pm 0.28$ & & $0.12 \pm 0.08$ & & $0.41 \pm 0.30$ & \\
\hline Endometrial infiltration & & NS & & NS & & NS \\
\hline Limited to endometrium & $0.15 \pm 0.18$ & & $0.08 \pm 0.06$ & & $0.34 \pm 0.27$ & \\
\hline$<1 / 2$ & $0.15 \pm 0.14$ & & $0.18 \pm 0.15$ & & $0.22 \pm 0.17$ & \\
\hline$\geq 1 / 2$ & $0.10 \pm 0.10$ & & $0.19 \pm 0.09$ & & $0.13 \pm 0.15$ & \\
\hline P53 & & 0.394 & & 0.112 & & 0.032 \\
\hline Negative & $0.16 \pm 0.15$ & & $0.19 \pm 0.14$ & & $0.20 \pm 0.15$ & \\
\hline Positive & $0.10 \pm 0.07$ & & $0.09 \pm 0.08$ & & $0.36 \pm 0.25$ & \\
\hline ER & & 0.217 & & 0.818 & & 0.395 \\
\hline Negative & $0.09 \pm 0.11$ & & $0.18 \pm 0.09$ & & $0.16 \pm 0.16$ & \\
\hline Positive & $0.16 \pm 0.15$ & & $0.19 \pm 0.15$ & & $0.23 \pm 0.19$ & \\
\hline PR & & 0.096 & & 0.877 & & 0.163 \\
\hline Negative & $0.03 \pm 0.04$ & & $0.20 \pm 0.13$ & & $0.10 \pm 0.14$ & \\
\hline Positive & $0.16 \pm 0.15$ & & $0.19 \pm 0.14$ & & $0.23 \pm 0.19$ & \\
\hline LVSI & & 0.853 & & 0.731 & & 0.203 \\
\hline No & $0.14 \pm 0.15$ & & $0.17 \pm 0.14$ & & $0.22 \pm 0.18$ & \\
\hline Yes & $0.15 \pm 0.09$ & & $0.19 \pm 0.11$ & & $0.13 \pm 0.16$ & \\
\hline
\end{tabular}

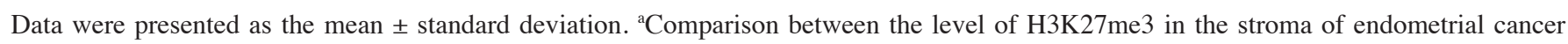
in different indexes, such as FIGO stage I and FIGO stage II-IV. ${ }^{b}$ Comparison between the level of H3K4me2 in the stroma of endometrial cancer in different indexes. ${ }^{\circ}$ Comparison between the level of H3K4me3 in the stroma of endometrial cancer in different indexes. NS, no statistic difference; FIGO, International Federation of Gynecology and Obstetrics; ER, estrogen receptor; PR, progesterone receptor; LVSI, lymph-vascular space invasion; H3K27me3, histone H3 lysine 27 trimethylation; H3K4me2, histone H3 lysine 4 dimethylation; H3K4me3, histone $\mathrm{H} 3$ lysine 4 trimethylation.

essential role in tumor promotion $(2,16)$; our previous study reached the same conclusion (17). Certain studies have widely associated H3K27me3 with gene silencing and transcriptional inhibition $(6,18)$; however, these studies have not achieved a consensus on the level of H3K27me3 and the significance of its aberrant expression in human tumorigenesis. Previous studies have suggested that the low expression level of $\mathrm{H} 3 \mathrm{~K} 27 \mathrm{me} 3$ in tumor tissues may enhance the expression of oncogenes and consequently promote tumor growth (19-22); however, Nakazawa et al (23) revealed no significant differences when comparing the expression levels of $\mathrm{H} 3 \mathrm{~K} 4 \mathrm{me} 2$ and $\mathrm{H} 3 \mathrm{~K} 27 \mathrm{me} 3$ in 85 cases of colorectal cancer with the paired normal colorectal tissues. Conversely, high expression levels of H3K27me3 were detected in other neoplasms $(24,25)$. In the present study, the expression level of H3K27me3 in the endometrial stroma was significantly lower in Type 1 endometrial cancer compared within the normal endometrium $(\mathrm{P}=0.043)$ and precancerous lesions $(\mathrm{P}<0.001)$. A low expression level of H3K27me3 may predict a more aggressive biological behavior in endometrial carcinoma; however, there were no significant differences in glandular epithelium of cancerous tissues and noncancerous tissues, which may be due to insufficient sample sizes. Stroma-tumor communication serves an important role in the genesis of neoplasia (26). The endometrium is composed of epithelium and lamina propria. The epithelium comprises columnar epithelial cells (endometrial epithelial cells) with a secretary function. Lamina propria consists of endometrial stromal cells (ESCs), immune cells, reticular fibers, matrix, blood vessels and nerves, forming the microenvironment of the epithelial cells. Tan et al (27) demonstrated that the epithelial-to-mesenchymal transition of prostate cancer cells was inhibited by adiponectin (ADN), which is also inversely correlated with the risk of endometrial cancer (28), with decreasing expression levels of H3K27me3 at the ADN promoter in 22RV1cells (a human prostate cancer cell line). To date, to the best of our knowledge, no previous study has focused on the association between adiponectin and H3K27me3 in stromal cells of endometrial cancer. Future 
studies are required to assess its potential role as a prognostic marker.

Presently, there is no definite understanding of H3K4me2 in cancer tissues. Previous studies suggested that it was positively associated with a poor prognosis in tumors $(29,30)$, whereas others held converse opinions $(31,32)$ or revealed no difference between the H3K4me2 expression levels and prognoses (23). In the present study, the H3K4me2 expression levels increased with the malignant degree of endometrial tissues in the epithelium, indicating that $\mathrm{H} 3 \mathrm{~K} 4 \mathrm{me} 2$ was involved in the oncogenesis of endometrial cancer. Furthermore, low expression levels of H3K4me2 in glandular epithelium of endometrial cancer were significantly associated with a clinical early FIGO stage $(\mathrm{P}=0.006)$. This finding indicated that endometrial cancer with high expression levels of H3K4me2 tended to be more invasive. Lei et al (33) and Liu et al (34) demonstrated that LIM-only protein 3 and PR domain containing 16 were associated with a poor prognosis in patients with astrocytoma and glioma. Both were indirectly inhibited by the tumor suppressor microRNA-101 with decreased H3K4me2 expression levels $(33,34)$. Cannuyer et al (35) revealed that MAGE family member A1 demethylation and activation in melanoma cells were associated with decreased expression levels of H3K9me2, and increased expression levels of $\mathrm{H} 3 \mathrm{ac}$ and $\mathrm{H} 3 \mathrm{~K} 4 \mathrm{me} 2$, where they encode tumor-specific antigens. Conversely, the stromal expression level of H3K4me2 was significantly lower in type 1 and type 2 endometrial cancer compared within the normal endometrium (all $\mathrm{P}=0.005$ ). Different expression levels of $\mathrm{H} 3 \mathrm{~K} 4 \mathrm{me} 2$ in the epithelium and stroma may indicate diverse mechanisms, and influences. Further studies are required to explore the role of histone modifications in the stroma in order to elucidate the interactive effect between the microenvironment and tumor cells.

The association between $\mathrm{H} 3 \mathrm{~K} 4 \mathrm{me} 3$ expression level and the prognosis of tumors also remains controversial. In an effort to assess the cellular expression level of H3K4me3 in $\mathrm{HCC}$ and its association with clinicopathological variables and outcomes, expression levels of $\mathrm{H} 3 \mathrm{~K} 4 \mathrm{me} 3$, and histone methyltransferase SET and MYND domain-containing protein 3 were investigated using western blotting, and immunohistochemistry in cell lines and tumor tissue microarrays from a well-characterized series of patients with HCC $(n=168)$ (29). The author compared two experimental results, and revealed that patients with maximum tumor diameters of $<5 \mathrm{~cm}$, a low tumor-node-metastasis score, no intravascular invasion and no recurrence of hepatocellular carcinoma had a lower expression level of H3K4me3 (P<0.05) (29). It was also demonstrated that as the expression level of $\mathrm{H} 3 \mathrm{~K} 4 \mathrm{me} 3$ increased, the prognosis of patients suffering from HCC worsened $(\mathrm{P}<0.0001)(36)$. However, this conclusion has been disputed by another report (37). In the present study, the expression levels of $\mathrm{H} 3 \mathrm{~K} 4 \mathrm{me} 3$ increased with the malignant degree of endometrial tissues in the epithelium; however, the specific underlying mechanism remains to be further explored. The factor p53 has a high level of association with tumors in humans. The overexpression of p53 is often observed in malignant tumors and can be a reliable marker for enhanced proliferation (38). In the present study, a low expression level of $\mathrm{H} 3 \mathrm{~K} 4 \mathrm{me} 3$ in the stroma was associated with p53-negativity $(\mathrm{P}=0.032)$, which predicts a benign prognosis in humans with endometrial cancer. Tang et al (39) demonstrated that enhancer/promoter-bound p53, via direct interactions, recruits p300 and SET1 complex (SET1C) to affect associatedH3K4me3 events via additional p300-SET1C interactions at the contiguous enhancer-core promoter region. Mungamuri et al (40) revealed that in response to p53 stabilization, its pro-apoptotic target promoters become enriched with the H3K4me3 epigenetic mark and its readers. Lauberth et al (41) also demonstrated a direct effect of $\mathrm{H} 3 \mathrm{~K} 4 \mathrm{me} 3$ on $\mathrm{p} 53$-dependent transcription. It may serve as a potential therapeutic target for the treatment of endometrial cancer. Future studies are required to further evaluate the biological function of $\mathrm{H} 3 \mathrm{~K} 4 \mathrm{me} 3$ in endometrial tissue and prospectively assess its potential role as a prognostic marker.

The majority of previous studies have focused on glands; however, few have paid attention to the stroma in endometrial cancer. The pathological diagnosis of endometrial cancer primarily depends on its glandular component in a high state of dysplasia. The stromal components of tumors (vascular, lymphatic interstitial and protein) serve an important role during the tumor growth and development. The roles of the stroma and its properties have not been studied extensively. ESCs and gland cells maybe homologous during embryogenesis for development from the Mullerian duct (42). ESC and gland cells express steroid receptors, meaning that they are regulated by steroid hormones in the peripheral blood (43). Furthermore, the development of cancer of gland cells accompanies the decline of ESCs until they disappear (44). The present study analyzed the expression level of histone methylation in the stroma of endometrial tumors, and proposed that the expression levels of $\mathrm{H} 3 \mathrm{~K} 27 \mathrm{me} 3$ and $\mathrm{H} 3 \mathrm{~K} 4 \mathrm{me} 2$ are low in the stroma of endometrial cancerous tumors. Low expression levels of $\mathrm{H} 3 \mathrm{~K} 4 \mathrm{me} 3$ in the stroma of endometrial cancerous tumors may be associated with poor prognosis.

\section{Acknowledgements}

The present study was supported by the National Natural Science Foundation of China (grant nos. 30973185 and 81572836) and by the Shanghai Science and Technology Committee (grant nos. 15140903200 and 16411953500).

\section{References}

1. Ferlay J, Soerjomataram I, Dikshit R, Eser S, Mathers C, Rebelo M, Parkin DM, Forman D and Bray F: Cancer incidence and mortality worldwide: Sources, methods and major patterns in GLOBOCAN 2012. Int J Cancer 136: E359-E386, 2015.

2. Gao Y, Hyttel P and Hall VJ: Regulation of H3K27me3 and H3K4me3 during early porcine embryonic development. Mol Reprod Dev 77: 540-549, 2010.

3. Benard A, Goossens-Beumer IJ, van Hoesel AQ, de Graaf W, Horati H, Putter H, Zeestraten EC, van de Velde CJ and Kuppen PJ: Histone trimethylation at H3K4, H3K9 and H4K20 correlates with patient survival and tumor recurrence in early-stage colon cancer. BMC Cancer 14: 531, 2014.

4. Deb M, Kar S, Sengupta D, Shilpi A, Parbin S, Rath SK, Londhe VA and Patra SK: Chromatin dynamics: H3K4 methylation and $\mathrm{H} 3$ variant replacement during development and in cancer. Cell Mol Life Sci 71: 3439-3463, 2014.

5. Tao H, Li H, Su Y, Feng D, Wang X, Zhang C, Ma H and $\mathrm{Hu}$ Q: Histone methyltransferase G9a and H3K9 dimethylation inhibit the self-renewal of glioma cancer stem cells. Mol Cell Biochem 394: 23-30, 2014. 
6. Ngollo M, Lebert A, Dagdemir A, Judes G, Karsli-Ceppioglu S, Daures M, Kemeny JL, Penault-Llorca F, Boiteux JP, Bignon YJ, et al: The association between histone 3 lysine 27 trimethylation (H3K27me3) and prostate cancer: Relationship with clinicopathological parameters. BMC Cancer 14: 994, 2014.

7. Park KC, Heo JH, Jeon JY, Choi HJ, Jo AR, Kim SW, Kwon HJ, Hong SJ and Han KS: The novel histone deacetylase inhibitor, N-hydroxy-7-(2-naphthylthio) hepatonomide, exhibits potent antitumor activity due to cytochrome-c-release-mediated apoptosis in renal cell carcinoma cells. BMC Cancer 15: 19, 2015.

8. Langevin SM, Kratzke RA and kelsey KT: Epigenetics of lung cancer. Transl Res 165: 74-90, 2015.

9. Yang WY, Gu JL, Zhen TM: Recent advances of histone modification in gastric cancer. J Cancer Res Ther 10 (Suppl) S240-S245, 2014.

10. Lyu T, Jia N, Wang J, Yan X, Yu Y, Lu Z, Bast RC Jr, Hua $\mathrm{K}$ and Feng W: Expression and epigenetic regulation of angiogenesis-related factors during dormancy and recurrent growth of ovarian carcinoma. Epigenetics 8: 1330-1346, 2013

11. Li LL, Xue AM, Li BX, Shen YW, Li YH, Luo CL, Zhang MC Jiang JQ, Xu ZD, Xie JH and Zhao ZQ: Erratum to: JMJD2A contributes to breast cancer progression through transcriptional repression of the tumor suppressor ARHI. Breast Cancer Res 18 : 114,2016

12. Stenchever MA, Rizk DE, Falconi G and Ortiz OC; FIGO task force on standard guidelines for training residents and fellows in urogynecology, female urolog: FIGO guidelines for training residents and fellows in urogynecology, female urology, and female pelvic medicine and reconstructive surgery. Int $\mathbf{J}$ Gynaecol Obstet 107: 187-190, 2009.

13. Jia N, Wang J, Li Q, Tao X, Chang K, Hua K, Yu Y, Wong KK and Feng W: DNA methylation promotes paired box 2 expression via myeloid zinc finger 1 in endometrial cancer. Oncotarget 7 : 84785-84797, 2016

14. Yanokura M, Banno K, Adachi M, Aoki D and Abe K Genome-wide DNA methylation sequencing reveals miR-663a is a novel epimutation candidate in CIMP-high endometrial cancer. Int J Oncol 50: 1934-1946, 2017.

15. Jones A, Teschendorff AE, Li Q, Hayward JD, Kannan A, Mould T, West J,Zikan M, Cibula D, Fiegl H, et al: Role of DNA methylation and epigenetic silencing of HAND2 in endometrial cancer development. PLoS Med 10: e1001551, 2013.

16. Li K, Chen MK, Situ J, Huang WT, Su ZL, He D and Gao X: Role of co-expression of c-Myc, EZH2 and p27 in prognosis of prostate cancer patients after surgery. Chin Med J (Engl) 126: 82-87, 2013.

17. Jia N, Li Q, Tao X, Wang J, Hua K and Feng W: Enhancer of zeste homolog 2 is involved in the proliferation of endometrial carcinoma. Oncol Lett 8: 2049-2054, 2014.

18. Gnani D, Romito I, Artuso S, Chierici M, De Stefanis C Panera N, Crudele A, Ceccarelli S, Carcarino E, D'Oria V, et al: Focal adhesion kinase depletion reduces human hepatocellular carcinoma growth by repressing enhancer of zeste homolog 2 . Cell Death Differ 24: 889-902, 2017.

19. Wei Y, Xia W, Zhang Z, Liu J, Wang H, Adsay NV, Albarracin C, Yu D, Abbruzzese JL, Mills GB, et al: Loss of trimethylation at lysine 27 of histone $\mathrm{H} 3$ is a predictor of poor outcome in breast, ovarian, and pancreatic cancers. Mol Carcinog 47: 701-706, 2008.

20. Rogenhofer S, Kahl P, Mertens C, Hauser S, Hartmann W, Büttner R, Müller SC, von Ruecker A and Ellinger J: Global histone H3 lysine 27 (H3K27) methylation levels and their prognostic relevance in renal cell carcinoma. BJU Int 109: 459-465, 2012

21. Shen Y, Guo X, Wang Y, Qiu W, Chang Y, Zhang A and Duan X: Expression and significance of histone $\mathrm{H} 3 \mathrm{~K} 27$ demethylases in renal cell carcinoma. BMC Cancer 12: 470, 2012.

22. Pellakuru LG, Iwata T, Gurel B, Schultz D, Hicks J, Bethel C, Yegnasubramanian S and De Marzo AM: Global levels of H3K27me3 track with differentiation in vivo and are deregulated by MYC in prostate cancer. Am J Pathol 181: 560-569, 2012.

23. Nakazawa T, Kondo T, Ma D, Niu D, Mochizuki K, Kawasaki T, Yamane T, Iino H, Fujii H and Katoh R: Global histone modification of histone $\mathrm{H} 3$ in colorectal cancer and its precursor lesions. Hum Pathol 43: 834-842, 2012.

24. He LJ, Cai MY, Xu GL, Li JJ, Weng ZJ, Xu DZ, Luo GY, Zhu SL and Xie D: Prognostic significance of overexpression of EZH2 and H3k27me3 proteins in gastric cancer. Asian Pac J Cancer Prev 13: 3173-3178, 2012
25. Au SL, Wong CC, Lee JM, Wong CM and Ng IO: EZH2-mediated $\mathrm{H} 3 \mathrm{~K} 27 \mathrm{me} 3$ is involved in epigenetic repression of deleted in liver cancer 1 in human cancers. PLoS One 8: e68226, 2013.

26. Hanahan D and Weinberg RA: Hallmarks of cancer: The next generation. Cell 144: 646-674, 2011.

27. Tan W, Wang L, Ma Q, Qi M, Lu N, Zhang L and Han B: Adiponectin as a potential tumor suppressor inhibiting epithelial-to-mesenchymal transition but frequently silenced in prostate cancer by promoter methylation. Prostate 75: 1197-1205, 2015.

28. Zeng F, Shi J, Long Y, Tian H, Li X, Zhao AZ, Li RF and Chen T: Adiponectin and endometrial cancer: A systematic review and meta-analysis. Cell Physiol Biochem 36: 1670-1678, 2015.

29. Mancuso M, Matassa DS, Conte M, Colella G, Rana G, Fucci L and Piscopo M: H3K4 histone methylation in oral squamous cell carcinoma. Acta Biochim Pol 56: 405-410, 2009.

30. Elsheikh SE, Green AR, Rakha EA, Powe DG, Ahmed RA, Collins HM, Soria D, Garibaldi JM, Paish CE, Ammar AA, et al: Global histone modifications in breast cancer correlate with tumor phenotypes, prognostic factors, and patient outcome. Cancer Res 69: 3802-3809, 2009.

31. Manuyakorn A, Paulus R, Farrell J, Dawson NA, Tze S, Cheung-Lau G, Hines OJ, Reber H, Seligson DB, Horvath S, et al: Cellular histone modification patterns predict prognosis and treatment response in resectable pancreatic adenocarcinoma: results from RTOG 9704. J Clin Oncol 28: 1358-1365, 2010.

32. Seligson DB, Horvath S, McBrian MA, Mah V, Yu H, Tze S, Wang Q, Chia D, Goodglick L and Kurdistani SK: Global levels of histone modifications predict prognosis in different cancers. Am J Pathol 174: 1619-1628, 2009.

33. Lei Q, Liu X, Fu H, Sun Y, Wang L, Xu G, Wang W, Yu Z, Liu C Li P, et al: miR-101 reverses hypomethylation of the PRDM16 promoter to disrupt mitochondrial function in astrocytoma cells. Oncotarget 7: 5007-5022, 2016.

34. Liu X, Lei Q, Yu Z, Xu G, Tang H, Wang W, Wang Z, Li G and Wu M: MiR-101 reverses the hypomethylation of the LMO3 promoter in glioma cells. Oncotarget 6: 7930-7943, 2015.

35. Cannuyer J, Loriot A, Parvizi GK and De Smet C: Epigenetic hierarchy within the MAGEA1 cancer-germline gene: Promoter DNA methylation dictates local histone modifications. PLoS One 8: e58743, 2013

36. He C, Xu J, Zhang J, Xie D, Ye H, Xiao Z, Cai M, Xu K, Zeng Y, $\mathrm{Li} \mathrm{H}$ and Wang J: High expression of trimethylated histone $\mathrm{H} 3$ lysine 4 is associated with poor prognosis in hepatocellular carcinoma. Hum Pathol 43: 1425-1435, 2012.

37. Ellinger J, Kahl P, Mertens C, Rogenhofer S, Hauser S, Hartmann W, Bastian PJ, Büttner R, Müller SC and von Ruecker A: Prognostic relevance of global histone H3 lysine 4 (H3K4) methylation in renal cell carcinoma. Int J Cancer 127: 2360-2366, 2010

38. Soussi T: Role of the $\mathrm{p} 53$ gene in human malignant tumors. A major discovery in oncology. Rev Prat 43: 2531-2535, 1993 (In French).

39. Tang Z, Chen WY, Shimada M, Nguyen UT, Kim J, Sun XJ, Sengoku T, McGinty RK, Fernandez JP, Muir TW and Roeder RG: SET1 and p300 act synergistically, through coupled histone modifications, in transcriptional activation by $\mathrm{p} 53$ Cell 154: 297-310, 2013

40. Mungamuri SK, Wang S, Manfredi JJ, Gu W and Aaronson SA: Ash2L enables P53-dependent apoptosis by favoring stable transcription pre-initiation complex formation on its pro-apoptotic target promoters. Oncogene 34: 2461-2470, 2015.

41. Lauberth SM, Nakayama T, Wu X, Ferris AL, Tang Z, Hughes SH and Roeder RG: H3K4me3 interactions with TAF3 regulate preinitiation complex assembly and selective gene activation. Cell 152: 1021-1036, 2013.

42. Stewart CA, Wang Y, Bonilla-Claudio M, Martin JF, Gonzalez G, Taketo MM and Behringer RR: CTNNB1 in mesenchyme regulates epithelial cell differentiation during Müllerian duct and postnatal uterine development. Mol Endocrinol 27: 1442-1454, 2013.

43. Ishikawa A, Kudo M, Nakazawa N, Onda M, Ishiwata T, Takeshita T and Naito Z: Expression of keratinocyte growth factor and its receptor in human endometrial cancer in cooperation with steroid hormones. Int J Oncol 32: 565-574, 2008.

44. Lessey BA, Albelda S, Buck CA, Castelbaum AJ, Yeh I, Kohler M and Berchuck A: Distribution of integrin cell adhesion molecules in endometrial cancer. Am J Pathol 146: 717-726, 1995. 